\title{
Exercise, sex and atrial fibrillation: arrhythmogenesis beyond Y-chromosome?
}

\author{
Eduard Guasch ${ }^{1 *}$, Lluís Mont ${ }^{1}$
}

${ }^{1}$ Arrhythmia Unit, Unitat de Fibril·lació Auricular, Hospital Clínic. Universitat de Barcelona and Institut d'Investigacions Biomèdiques August Pi i Sunyer (IDIBAPS), Barcelona, Catalonia, Spain.

* To whom correspondence should be sent.

Eduard Guasch, MD, PhD.

Villarroel 170.

08036 Barcelona, Catalonia, Spain.

Tel. (+34) 932715551

Fax. (+34) 934513045

eguasch@clinic.ub.es

The Corresponding Author has the right to grant on behalf of all authors and does grant on behalf of all authors, an exclusive licence on a worldwide basis to the BMJ Publishing Group Ltd and its Licensees to permit this article (if accepted) to be published in HEART editions and any other BMJPGL products to exploit all subsidiary rights.

Word count: 1417 (excluding Title page and References). 


\section{Exercise, sex and atrial fibrillation: arrhythmogenesis beyond Y-chromosome?}

Although prevailing research trends favour large clinical trials and registries, meticulous observation during daily clinical practice remains a valuable source for hypothesis generation in medical research. Clinical experience has allowed the identification of several risk factors in the cardiovascular field. For instance, two groups of investigators noticed in parallel that patients with atrial fibrillation (AF) but no cardiovascular disease used to be healthy, fit, heavily trained middle-aged men. By the end of the $1990 s^{\prime}$ and beginning of the $2000 s^{\prime}$, a series of articles were published confirming their observations: a history of continued endurance training associated with an increased risk of AF. Initial small casecontrol and cohort studies almost exclusively included men in order to accurately and homogeneously fit their observations and hypothesis, with women representing only $2 \%$ of all patients (Figure). The link between physical activity and AF remained suspicious of bias and was largely disputed in the scientific community until the publication of large epidemiological studies. Similarly to previous small studies, these were initially carried out in men; women were progressively included in subsequent works (Figure). Finally, as evidence of this association had already been firmly established in men, an increasing need to test its validity in women aroused. Two studies exclusively focusing in women recalled initial clinical observations:[1,2] women were not seemingly affected by the AF-risks of exercise.

A work by Drca et al. in this issue of Heart provides novel insights into the association of physical activity and AF in 39,227 women included in the prospective Swedish Mammography cohort.[3] In 1997, participants averaging 60 years old filled a baseline questionnaire assessing time spent in leisure-time physical activity and for transportation purposes. As opposed to previous works, $[1,2]$ participants were also inquired about their recalled exercise habits while young adults at 30 years old. The 12-year period following baseline time-point was reviewed in electronic medical records at the national level to collect AF diagnoses. Their main findings can be summarized around two important ideas. 
A first remarkable message from Drca et al. is that ongoing moderate or high-intensity physical activity at 60 years old prevents from AF. With no doubt, this should be an additional, compelling item to add to the backpack of physical activity benefits in the elderly. A $20 \%$ decreased risk of $\mathrm{AF}$ in the most active group remained after adjusting for several concomitant cardiovascular risk factors. This brings us some food for thought...

Is multivariate adjustment accurate enough in the elderly? Frailty in aged individuals is a quite intuitive concept, but hard to measure and include in a multivariate analysis. More fragile individuals are less likely to exercise; how this under-adjustment of data could have changed final conclusions is unclear.

Should exercise-promoted outcomes be adjusted for cardiovascular risk factors? How should results be interpreted? It is well-known that physical activity improves cardiovascular risk profile, and thus some hypertension- or dyslipidemia-mediated beneficial effects might be lost after multivariate adjustment. Certainly, an adjusted analysis yields important data on the isolated effects of exercise after associated changes in cardiovascular profile have been excluded. However, it is worth noting that the adjusted relative risk is likely underestimating the true benefit of physical activity in the community.

Which are the mechanisms mediating decreased AF incidence after adjusting for cardiovascular risk factors? In addition to an improved cardiovascular risk profile, physical activity is known to associate chronic anti-inflammatory and anti-aging effects. Are these enough to produce such a large $20 \%$ decrease in $A F$ incidence in the most active group?

A second conclusion, likely the most challenging one, is that physical activity at 30 years old does not increase AF risk later in the life of women. These results contrast with previous data from the same research group in men.[4] So at this point in time it is becoming quite clear that the wellrecognized association of exercise and AF does not apply to women. The reasons underlying different responses to the same stimulus remain obscure. A simple, straightforward answer is that women are, somehow, protected against the deleterious consequences of intense exercise. Indeed, data in the 
literature support that cardiac adaptation to physical activity differs in both genders. After a comparable amount of exercise, structural remodeling including left atrial dilation is more intense in male athletes,[5] consistent with experimental data showing an attenuated response to hemodynamic overload in female rats.[6] An acute increase in right atrial pressure does produce less changes in atrial electrophysiology in women than it does in men.[7] On the other hand, some data point to an enhanced atrial proarrhythmogenic substrate in women. Endurance exercise induces a transient, intensity-dependent systemic pro-inflammatory status after exercise bouts that might contribute to atrial deleterious remodeling. Although controversial data has been published, the inflammation cascade might be amplified in women after similar amounts of exercise.[8] Autonomic tone plays a critical role in exercise-induced AF, and a similar training load yields a deeper vagal enhancement in women than in men.[5] Whether the resulting remodeling is similarly arrhythmogenic in men and women still needs to be assessed.

Nevertheless, differences in gender-associated AF risk likely go beyond Y-chromosome susceptibility. Environmental determinants are playing a critical role in exercise-induced AF. Exerciseinduced AF is generally diagnosed in patients involved in regular high-intensity endurance activities such as marathon running, cycling and cross-country sky. However, historical circumstances have caused women to be much less engaged in intense training than men. In this regard, marathon running might be seen as a rough estimator of physical activity habits of a population. Data from Drca et al. needs to be placed into context: a simple arithmetic operation shows that women in this study were asked about the leisure-time physical activity habits they were engaged in 1967 (the year at which they were 30 years old). It was in 1967 that Kathrine Switzer became the first woman to officially run the Boston Marathon, a year in which 740 male participants had already been registered. In contrast, more than 40\% of the 26,610 athletes finishing the Boston Marathon in 2015 were women. These facts provide an estimate of the low leisure-time physical activity burden in women some 50 years ago and how society has evolved since then. Can results derived from 50 years ago be applied today after such a dramatic change? 
In June $23^{\text {rd }} 2014$, Time magazine published a polemical cover and inside article entitled "Eat Butter". In this article, the authors suggested that, as US population increasingly feared saturated fat, sugar consumption exponentially increased and initiated an obesity and metabolic syndrome pandemic. Dietary guidelines recommending a reduction in fat ingestion were first published by the US Department of Agriculture in 1980; since then, publicly available data from the Centers for Disease Control and Prevention show that age-adjusted prevalence of obesity $\left(\mathrm{BMl}>30 \mathrm{~kg} / \mathrm{m}^{2}\right)$ has increased from $22.9 \%$ to $34.9 \%$ and diabetes prevalence raised from $3.7 \%$ to $8.5 \%$. This paradoxical response underlines the need for a close follow-up of significant modifications in the population behaviour and their (un-)expected consequences. It is essential to interpret actual data, but we should be able to foresee how their determinants might change over time. Where do we stand now with exercise-induced AF in women? Undoubtedly, women practising as much physical activity as that in the 1960s' are not an increased risk. Are women nowadays running a marathon at risk of AF? The answer is that we do not known, and further data is warranted in the upcoming years. The work by Drca et al. is a much needed departure point for future follow-up studies in which changes in the intensity of exercise will be challenged against data from the 1960s'. Women are now engaged in more regular and more intense physical activity -fortunately. We should definitely keep an eye on it.

\section{Funding}

This work has received funding from the European Union's Horizon 2020 research and innovation programme under grant agreement No 633196 (CATCH ME project) and from Instituto de Salud Carlos III - Fondo de Investigaciones Sanitarias (PI13/01580). 


\section{References}

1 Everett $\mathrm{BM}$, Conen D, Buring JE, et al. Physical activity and the risk of incident atrial fibrillation in women. Circ Cardiovasc Qual Outcomes 2011;4:321-7.

doi:10.1161/CIRCOUTCOMES.110.951442

2 Azarbal F, Stefanick ML, Salmoirago-Blotcher E, et al. Obesity, physical activity, and their interaction in incident atrial fibrillation in postmenopausal women. J Am Heart Assoc 2014;3. doi:10.1161/JAHA.114.001127

3 Drca N, Wolk A, Jensen-Urstad M, et al. Physical activity is associated with a reduced risk of atrial fibrillation in a middle-aged and elderly women. Heart 2015.

4 Drca N, Wolk A, Jensen-Urstad M, et al. Atrial fibrillation is associated with different levels of physical activity levels at different ages in men. Heart 2014;100:1037-42.

doi:10.1136/heartjnl-2013-305304

$5 \quad$ Wilhelm $\mathrm{M}$, Roten $\mathrm{L}$, Tanner $\mathrm{H}$, et al. Gender differences of atrial and ventricular remodeling and autonomic tone in nonelite athletes. Am J Cardiol 2011;108:1489-95.

doi:10.1016/j.amjcard.2011.06.073

$6 \quad$ Weinberg EO, Thienelt CD, Katz SE, et al. Gender differences in molecular remodeling in pressure overload hypertrophy. J Am Coll Cardiol 1999;34:264-73. doi:10.1016/S07351097(99)00165-5

7 Tse HF, Oral $\mathrm{H}$, Pelosi F, et al. Effect of gender on atrial electrophysiologic changes induced by rapid atrial pacing and elevation of atrial pressure. J Cardiovasc Electrophysiol 2001;12:986-9.

8 Gill SK, Teixeira A, Rama L, et al. Circulatory endotoxin concentration and cytokine profile in response to exertional-heat stress during a multi-stage ultra-marathon competition. Exerc Immunol Rev 2015;21:114-28.http://www.ncbi.nlm.nih.gov/pubmed/25830597 (accessed 6 May2015). 


\section{Figure legend}

Graphical summary of some representative studies assessing exercise-induced atrial fibrillation risk depending on the gender composition and design of the study. Upper panel: overall percentage of women included for each type of study, from initial small case-control/cohorts studies $(<1,000$ individuals included) to male/both gender or women-exclusive epidemiological studies $(>3,000$ individuals). Lower panel: relative risk or odds ratio of exercise-induced AF (sedentary vs the most intense group) in these studies, represented along their publication year and coloured according to the study design. References (S1-S16) of the studies are reported in Online Supplementary Material.

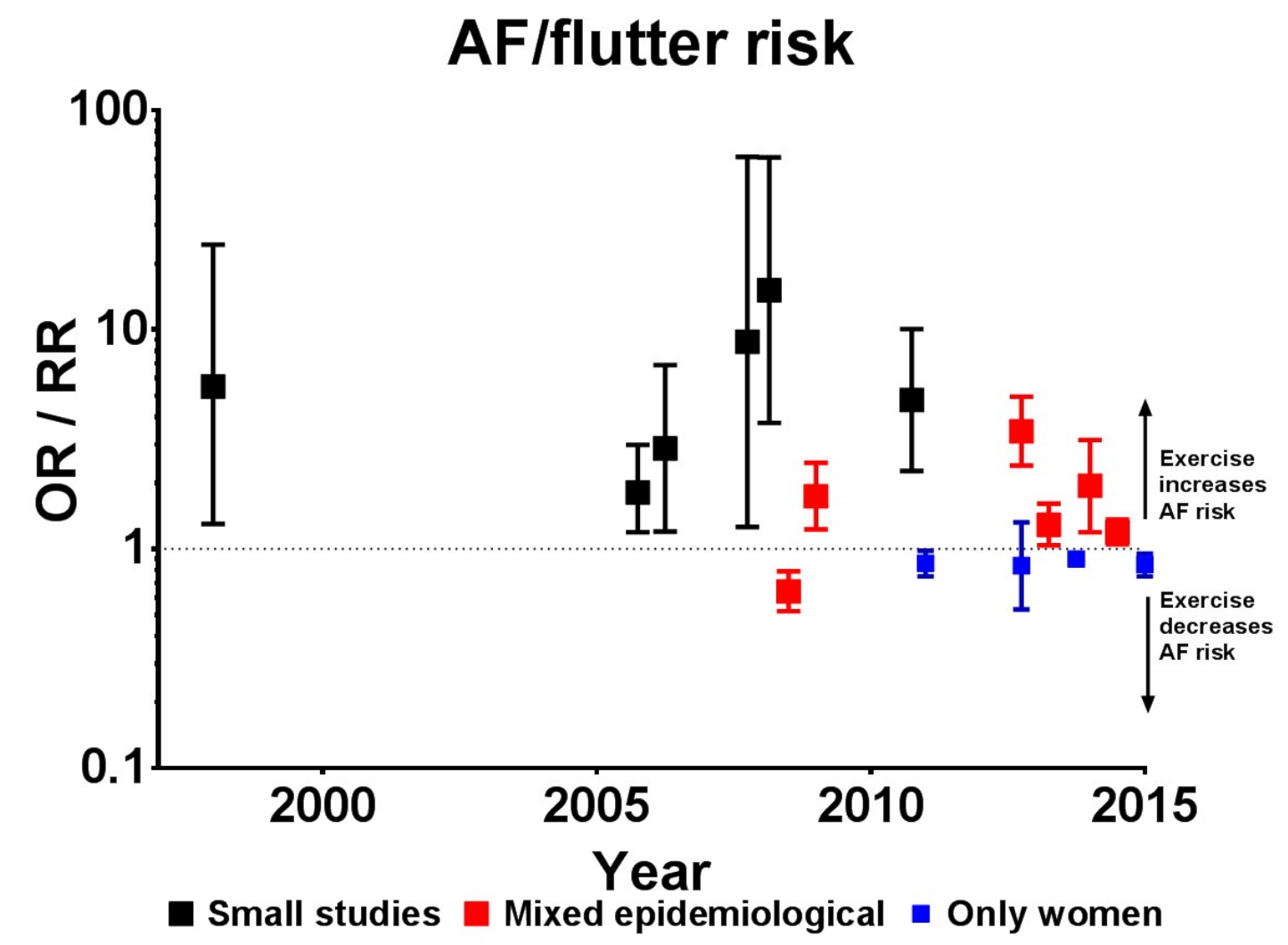




\section{Bibliographic references for studies shown in the Figure}

Note that studies here are identified in the same order (within each study design) as they appear in the Figure.

\section{Small cohort/case control studies}

Karjalainen J, Kujala UM, Kaprio J, et al. Lone atrial fibrillation in vigorously exercising middle aged men: case-control study. BMJ 1998;316:1784-5.

Heidbüchel H, Anné W, Willems R, et al. Endurance sports is a risk factor for atrial fibrillation after ablation for atrial flutter. Int J Cardiol 2006;107:67-72.

Elosua R, Arquer A, Mont L, et al. Sport practice and the risk of lone atrial fibrillation: a casecontrol study. Int J Cardiol 2006;108:332-7.

Molina L, Mont L, Marrugat J, et al. Long-term endurance sport practice increases the incidence of lone atrial fibrillation in men: a follow-up study. Europace 2008;10:618-23.

Baldesberger S, Bauersfeld U, Candinas R, et al. Sinus node disease and arrhythmias in the long-term follow-up of former professional cyclists. Eur Heart J 2008;29:71-8. For this study, Odds ratio and confidence intervals (not originally provided in the article) were calculated with the correction suggested in $x x x x x$.

Mont L, Tamborero D, Elosua R, et al. Physical activity, height, and left atrial size are independent risk factors for lone atrial fibrillation in middle-aged healthy individuals. Europace 2008;10:15-20.

Claessen G, Colyn E, La Gerche A, et al. Long-term endurance sport is a risk factor for development of lone atrial flutter. Heart 2011;97:918-22.

\section{Male/both gender epidemiological studies}

Mozaffarian D, Furberg CD, Psaty BM, et al. Physical activity and incidence of atrial fibrillation in older adults: the cardiovascular health study. Circulation 2008;118:800-7.

Aizer A, Gaziano JM, Cook NR, et al. Relation of vigorous exercise to risk of atrial fibrillation. Am J Cardiol 2009;103:1572-7.

Thelle DS, Selmer R, Gjesdal K, et al. Resting heart rate and physical activity as risk factors for lone atrial fibrillation: a prospective study of 309540 men and women. Heart 2013;:16. Data for men and women are provided separately as they are in the original publication.

Andersen K, Farahmand B, Ahlbom A, et al. Risk of arrhythmias in 52755 long-distance crosscountry skiers: A cohort study. Eur Heart J 2013;34:3624-31. 
Myrstad M, Nystad W, Graff-Iversen S, et al. Effect of Years of Endurance Exercise on Risk of Atrial Fibrillation and Atrial Flutter. Am J Cardiol 2014;114:1229-33. Data for atrial flutter risk is shown.

Drca N, Wolk A, Jensen-Urstad M, et al. Atrial fibrillation is associated with different levels of physical activity levels at different ages in men. Heart 2014;100:1037-42.

\section{Only women epidemiological studies}

Everett $\mathrm{BM}$, Conen $\mathrm{D}$, Buring JE, et al. Physical activity and the risk of incident atrial fibrillation in women. Circ Cardiovasc Qual Outcomes 2011;4:321-7. doi:10.1161/CIRCOUTCOMES.110.951442

Azarbal F, Stefanick ML, Salmoirago-Blotcher E, et al. Obesity, physical activity, and their interaction in incident atrial fibrillation in postmenopausal women. J Am Heart Assoc 2014;3. doi:10.1161/JAHA.114.001127

Drca N, Wolk A, Jensen-Urstad M, et al. Physical activity is associated with a reduced risk of atrial fibrillation in a middle-aged and elderly women. Heart 2015. In Press. 